\section{POLÍTICAS HACIA VILLAS Y CASAS TOMADAS DE LA CIUDAD DE BUENOS AIRES: TENSIONES ENTRE LA INCLUSIÓN Y LA EXCLUSIÓN}

Felipe Ochsenius*, María Carman**, Vanina Lekerman***, Marina Wertheimer****

\section{Resumen}

En este trabajo abordamos las características distintivas de las políticas hacia villas y, posteriormente, hacia casas ocupadas de la Ciudad Autónoma de Buenos Aires, Argentina, entre los años 1950 y 2002. Analizamos el modo en que fueron desplegadas un cierto conjunto de políticas habitacionales en sucesivas etapas autoritarias y democráticas, las cuales oscilaron entre la radicación/ erradicación e inclusión/exclusión. Nuestro objetivo es profundizar en la trayectoria de casi un siglo de políticas hacia los sectores populares que habitan en villas y/o casas tomadas de la Ciudad de Buenos Aires, cuyos signos prevalecientes han sido la errancia, la parcialidad y la violencia. A lo largo de nuestra exposición sostenemos que los desplazamientos de los sectores sociales más vulnerables

\section{POLICIES FOCUSED ON ILLEGALLY OCCUPIED VILLAGES AND DWELLINGS IN BUENOS AIRES: INCLUSION- EXCLUSION TENSION}

Felipe Ochsenius*, María Carman**, Vanina

Lekerman***, Marina Wertheimer****

\section{Abstract}

This paper addresses the distinctive characteristics of policies focused on illegally occupied villages and dwellings in the Autonomous City of Buenos Aires, Argentina, over the 1950-2002 period. It also analyzes the implementation of a certain set of housing initiatives in successive authoritarian and democratic eras, which ranged from establishment/eradication and inclusion/ exclusion. The objective of this research is to provide further insights into the 100-year-old history of policies oriented towards popular sectors who live in illegally occupied villages and dwellings in Buenos Aires and whose prevalent hallmarks are vagrancy, partiality and violence. This study argues that housing policies are 
parecen haberse constituido como una constante de este conjunto de políticas habitacionales, basados en la concepción, más o menos tácita, de que el lugar "natural" de residencia de los sectores populares es fuera de la ciudad capital.

\section{PALABRAS CLAVE: CIUDAD DE BUENOS AIRES; DESPLAZAMIENTOS; ERRADICACIÓN; RADICACIÓN; VIVIENDA SOCIAL}

\author{
Recibido: 09-03-2016
}

Aceptado: 30-09-2016

* Argentina. Geógrafo de la Pontificia Universidad Católica de Chile, 2005. Posgrado en Desarrollo Local y Economía Local, FLACSO Argentina, 2007. Maestría en Antropología Social y Política, 2012 - 2015. Geógrafo del Área de Análisis Espacial, Dirección General de Salud Ambiental, Autoridad de la Cuenca Matanza Riachuelo. Forma parte del equipo "Antropología, Ciudad y Naturaleza", Área de Estudios Urbanos, Instituto de Investigaciones Gino Germani, Universidad de Buenos Aires. Correo electrónico: basalto1@gmail.com.

* Argentina. Doctora en Antropología, Facultad de Filosofía y Letras, Universidad de Buenos Aires. Directora Equipo «Antropología, Ciudad y Naturaleza", Área de Estudios Urbanos, Instituto de Investigaciones Gino Germani, Universidad de Buenos Aires. Correo electrónico: mariacarman1971@gmail.com.

*** Argentina. Doctora en Antropología, Facultad de Filosofía y Letras, Universidad de Buenos Aires. Docente Programa UBA 21. Correo electrónico: vaninalekerman@gmail.com.

*** Argentina. Licenciada en Ciencia Política, UBA. Magister en Periodismo, Universidad de San Andrés. Doctoranda en Ciencias Sociales, Universidad Nacional de General Sarmiento - Instituto de Desarrollo Económico. Correo electrónico: lasmarunas@ gmail.com.

194 revista invi31(88): 193-215, noviembre de 2016 constantly displacing vulnerable social groups according to the premise that the "natural" place of residence of these groups can be found outside the capital city.

\section{KEYWORDS:CITYOFBUENOSAIRES;DISPLACEMENT; ERADICATION; RADICATION; SOCIAL HOUSING}

Received: 09-03-2016

Accepted: 30-09-2016

* Argentina. Geographer, Pontifical Catholic University of Chile, 2005. Postgraduate degree in Local Development and Local Economy, FLACSO Argentina, 2007. MSc in Social and Political Anthropology, 2012-2015. Geographer, Spatial Analysis Area, Directorate-General for Environmental Health, Local Authority for Cuenca Matanza Riachuelo. Member of the "Anthropology, City and Nature" group. Urban Studies Area, Gino Germani Research Institute, University of Buenos Aires. Email: basalto1@gmail.com

* Argentina. PhD in Anthropology, Faculty of Philosophy and Literature, University of Buenos Aires. Director, "Anthropology, City and Nature" group, Urban Studies Area, Gino Germani Research Institute, University of Buenos Aires. Email: mariacarman1971@gmail.com

*** Argentina. PhD in Anthropology, Faculty of Philosophy and Literature, University of Buenos Aires. Professor, UBA 21 Program. Email: vaninalekerman@gmail.com

**** Argentina. BA in Political Science, UBA. MSc in Journalism, University of San Andrés. PhD student in Social Science, Universidad Nacional de General Sarmiento - Institute for Economic Development. Email: lasmarunas@gmail.com. 


\section{Introducción}

Los programas de erradicación de villas de emergencia en Argentina -con mayor o menor énfasis y violencia-, fueron llevados a cabo por distintos gobiernos entre 1955 y 1983․ A partir del retorno a la democracia, en 1983, la política habitacional de los sectores populares dio un giro hacia políticas de radicación e integración de las villas, lo cual no significó, empero, el fin de los desplazamientos generados por estas.

Durante la década de 1990, se registró un auge de desalojos ya no de villas -que, tanto a nivel local como en la región latinoamericana, en general fueron adquiriendo cierta legitimidad a la hora de erigirse como interlocutores válidos ante el Estado- sino enfocados en aquellas ocupaciones atomizadas o individuales, públicamente conocidas como ocupaciones ilegales. Estas se basaron en la toma de inmuebles ociosos (casas, departamentos, o bien propiedades no aptas para la vivienda como galpones o fábricas), ubicados mayormente en la zona sur de la ciudad capital ${ }^{2}$. A partir de la creciente valorización inmobiliaria posterior a la superación de la crisis que atravesó el país en 2001, los ocupantes fueron progresivamente objeto de una nueva ola de intolerancia por parte del poder estatal y los desalojos pedagógicos dominaron

1 Vitale, 2009; Blaustein, 2001.

2 Carman, 2007. la escena ${ }^{3}$. En forma simultánea, surgieron asentamientos o nuevas villas, a cuyos habitantes les fueron ofrecidos magros subsidios monetarios a cambio de su desplazamiento. En el marco de procesos de valorización del suelo y especulación inmobiliaria, la gestión del gobierno de la Ciudad de Buenos Aires fue legitimando estas acciones de desalojo bajo la premisa de la recuperación del espacio público.

Nuestro propósito es analizar las diferentes formas de desalojos implementados desde la segunda mitad del siglo pasado hasta comienzos del presente siglo, centrándonos en los siguientes aspectos:

- La lógica de desalojos acelerados y de una intensa violencia en sus procedimientos.

- Las políticas de omisión y tolerancia hacia las ocupaciones de los sectores populares.

- La implementación de ciertas políticas habitacionales de corte asistencialista.

- Los desalojos "negociados" y aquellos restringidos a un costado disciplinar.

Tal como veremos en las siguientes secciones, las intervenciones en cuestión habilitaron ciertas prácticas y procedimientos tendientes a la segregación de los sectores populares que habitan en esta ciudad capital.

3

Ibídem, 2007, p. 5. 


\section{Metodología}

En este artículo se exponen resultados a los que hemos llegado a través de una combinación de métodos. En primer lugar, hacemos una revisión bibliográfica de investigaciones antropológicas y sociológicas centradas en las políticas de intervención en villas y, posteriormente, en casas ocupadas en la ciudad de Buenos Aires en el período comprendido entre 1955 y 1990.

Para analizar las características que éstas asumieron en el período de 1990 hasta el 2002, nos focalizamos en investigaciones propias conducidas por los autores del artículo, refrendadas con datos censales del Instituto Nacional de Estadística y Censos (INDEC) de la Argentina.

\section{Desalojos de urgencia y máxima violencia: los programas de erradicación}

En consonancia con las tendencias a nivel regional prevalecientes en la segunda mitad del siglo XX, las actitudes de los poderes públicos para con el sector informal del suelo urbano han oscilado entre la permisividad y la intolerancia ${ }^{4}$. La primera implica una aceptación de la

4 Caravaca Barroso y Villalón, 1992-1993. permanencia del habitar informal, a través de la provisión de los mecanismos legales para volver efectiva la radicación. La segunda, en cambio, conlleva la condena y la represión a sus habitantes. A lo largo de la historia de las políticas hacia villas y asentamientos en la ciudad de Buenos Aires puede identificarse, sin embargo, un carácter predominantemente excluyente en las políticas urbanas, que se corresponde con un imaginario generalizado que reivindica que "hay que merecer" la ciudad $^{5}$. La frase, acuñada por Oszlak, reconocido cientista social argentino, refleja la necesidad de las elites de establecer un "orden urbano" para la metrópolis de Buenos Aires, según el cual la ciudad capital debe ser "la vidriera del país", habitada por clases medias y altas, confinando a los pobres a la periferia ${ }^{6}$. Bajo este principio, numerosas han sido las iniciativas estatales destinadas a "limpiar" la ciudad de sus habitantes indeseados, junto a sus formas de habitar, desplazándolos del centro de la ciudad a partir de diversos tipos de intervención: erradicación de villas miseria; desalojo de casas tomadas; relocalizaciones y políticas de radicación con una completa formulación normativa, pero con alcances limitados en lo que refiere a su ejecución.

Las villas miseria, también conocidas como villas de emergencia o simplemente villas, remontan sus orígenes a la década de 1930, su presencia cobró mayor envergadura a partir de los años cuarenta,

\footnotetext{
5 Oszlak, 1991.

6 Oszlak emplea este concepto para referirse a la política urbana durante la última dictadura militar. Creemos que el merecer la ciudad refleja también el imaginario dominante de contar con una "ciudad blanca" rodeada de un anillo de pobladores de sectores populares.
} 
en simultáneo al proceso argentino de industrialización sustitutiva de importaciones. La migración hacia las grandes urbes, producto de la descomposición de las economías rurales, fue generando una tasa de crecimiento de la población urbana mayor a la del crecimiento industrial, lo que provocó una masa de marginados del proceso productivo ${ }^{7}$. Con una inserción económica inestable, los nuevos residentes quedaron también relegados del acceso a una propiedad formal, asentándose en viviendas precarias con tramas urbanas irregulares; vale decir, sin plano ni construcción en forma de grilla o damero.

Dada su centralidad y alta visibilidad, las villas fueron, desde temprano, objeto de una política pública de sesgo expulsivo: en lugar de provisión de vivienda alternativa, los programas de política urbana buscaron desplazar a los habitantes pobres a la periferia urbana. En los códigos y planificaciones urbanas de distintas ciudades latinoamericanas, se suele definir a las villas (o a su denominación local) como aberraciones que no pueden aparecer en el mapa oficial de las ciudades y que deben ser erradicadas, así como prohibida su construcción ${ }^{8}$. Tal fue el caso de los programas de erradicación de

7 Clichevsky, 2000.

8 Jaramillo, 1993. villas de emergencia llevados a cabo por distintos gobiernos argentinos entre 1955 y $1983^{9}$. Especialmente el período 1976-1983 -coincidente con la última dictadura militar- se caracterizó por una lógica de desalojos acelerados de sectores populares y procedimientos de una violencia inédita ${ }^{10}$, cuestión que fue replicada en otros países de la región bajo regímenes de facto con represión de las distintas formas de asentamientos espontáneos, produciendo otras modalidades de habitar como el "allegamiento"11 y aumentando considerablemente el déficit habitacional existente ${ }^{12}$.

Los primeros planes de erradicación fueron implementados bajo el gobierno de facto autoproclamado "Revolución Libertadora" (1955-1958). En 1956, bajo el gobierno del general Pedro Aramburu, la entonces Comisión Nacional de la Vivienda (CNV) estableció, por primera vez, una política destinada a las villas de emergencia ${ }^{13}$.

El pensamiento dominante durante este período suponía que estas modalidades habitacionales eran espacios caóticos donde reinaba la anomia y eran focos de peligrosidad y hasta de contaminación ambiental ${ }^{14}$. De modo que las villas eran vistas no

\footnotetext{
9 Vitale, 2009; Blaustein, 2001

10 Hermitte y Boivin, 1985.

11 Hidalgo, 2007.

12 Mac Donald, 1994, Ducci, 1997.

13 Mediante la CNV se puso en marcha una "Plan de Acción Inmediata", el cual fue el primer plan de erradicación de las villas.

14 Hajek, 1995.
} 
solamente como un problema de déficit habitacional, sino también como una patología social generadora de otros problemas de orden moral, social y urbano ${ }^{15}$. Ello legitimó que se implementara la erradicación forzosa, pero paralelamente se intentó dar algún tipo de respuesta a los erradicados a través de la construcción de conjuntos habitacionales ubicados en zonas periféricas, concebidos como unidades vecinales con centros comunales ${ }^{16}$. No obstante, las soluciones habitacionales implementadas en dicho período resultaron deficitarias tanto cuantitativa como cualitativamente. Numerosos son los estudios que demuestran el fracaso de este tipo de políticas de erradicación implementadas en la región, tanto por la insuficiencia del número de viviendas ofrecidas, como por la constante afluencia de inmigrantes que se reproduce año a año en los países de la región ${ }^{17}$. En Buenos Aires, se osciló entre políticas asistencialistas y de tolerancia hacia los sectores populares y aquellas políticas que implementaban dispositivos institucionales de control y requisa de dicha población. Algunos autores subrayan una trayectoria común entre la política de vivienda y la reproducción del problema habitacional18: desalojos, solución inadecuada

\footnotetext{
15 Cuenya, 1997.

16 Blaustein, 2001

17 Geisse, 1982; Hardoy y Satterhwaite, 1987; Figueroa Salas, 1989.

18 Yujnovsky 1984, Vitale, 2009.
}

198 revista invi 31(88): 193-215, noviembre de 2016 y ampliación del déficit habitacional que se busca combatir. Esta trayectoria fue seguida por un período en el que las reivindicaciones de la población villera organizada -como la Federación de Villas de Emergencia- tuvieron cierta recepción en la esfera institucional, en donde primó una actitud de tolerancia y diálogo con los sectores populares. Se trató del período de gobiernos pseudoconstitucionales, con el peronismo proscripto y la democracia controlada (1958-1966), bajo los cuales la entonces Municipalidad de la Ciudad de Buenos Aires implementó varios planes de vivienda, en conjunto con organismos financieros internacionales como el Fondo Monetario Internacional (FMI).

Las erráticas políticas habitacionales que se forjaron entre 1955 y 1966 se explicitaron en prácticas concretas de control y medidas higiénicas hacia las villas $^{19}$. Asimismo, se diseñaron políticas que sentaron las bases para la posterior implementación de ciertas prácticas expulsivas. Al mismo tiempo en que se adoptó una actitud de tolerancia con los sectores populares, se establecieron medidas pedagógicas de "adaptación" a la "vida civilizada" y mecanismos tendientes a la estigmatización de la población

19 A principios del siglo $\mathrm{XX}$, los problemas urbanos fueron foco de atención para higienistas y funcionarios gubernamentales, quienes emplearon discursos vinculados a la moral y al orden social. Durante el gobierno peronista (1945-1955) se rompió con este discurso asociado al positivismo higienista, pero posteriormente se volvió sobre las políticas que reivindicaban el control urbano y las medidas higiénicas. 
alojada en las villas, brindando los lineamientos ideológicos y políticos para la posterior consolidación de instituciones que habrían de llevar adelante políticas habitacionales más agresivas ${ }^{20}$.

Durante la presidencia de Arturo Illia (1963-1966), la política habitacional viró hacia acciones tendientes a "educar" y relocalizar a los sectores populares. Por un lado, aquellas personas que se alojaban en las villas debían atravesar por un "proceso de adaptación" mediante el pasaje por un alojamiento de viviendas a corto plazo, seguido por el traslado a viviendas definitivas, con el objeto de "traspasar la barrera" de volver a alojarse en las villas. Por otro lado, comienza a estigmatizarse a sus habitantes -dentro de la legislación existente- bajo la categoría jurídica de intrusos, utilizada hacia aquellos que se opusieran a la erradicación.

La posibilidad de las poblaciones villeras de hacer escuchar sus reclamos fue breve. Bajo la dictadura del general Juan Carlos Onganía (1966-1970), la violencia cobró intensidad, con un mayor desarrollo de una planificación expulsiva. En otras palabras, la política habitacional fue delineada en base a la legalización de prácticas expulsivas hacia los

20 Lekerman, 2014. sectores populares que habitaban la ciudad. Bajo el mandato de Onganía, se implementó el Plan de Erradicación de Villas de Emergencia (PEVE), cuya materialización se llevó a cabo a través del Ministerio de Bienestar Social para todo el territorio nacional. Las áreas de ejecución fueron las Secretarías de Asistencia y Promoción de la Comunidad y la Secretaría de Vivienda, contemplando tres instancias: la erradicación; el alojamiento provisorio, y la solución habitacional definitiva ${ }^{21}$.

El plan de erradicación de villas contempló la erradicación y el posterior alojamiento "transitorio" de 70.000 villeros de ciudad de Buenos Aires y de otros 210.000 del Gran Buenos Aires, contabilizando un total de 280.000 erradicaciones y realojamientos en el Área Metropolitana de Buenos Aires. Los realojamientos se llevaron a cabo en un nuevo y experimental tipo de vivienda: los Núcleos Habitacionales Transitorios (NHT), destinados a ser un paso obligado para las familias previo al acceso a su vivienda definitiva. La finalidad que tendría esta modalidad habitacional era "educar", "civilizar" y "generar conductas adaptativas" hacia la nueva vivienda ${ }^{22}$. 
El plan se cumplió sólo parcialmente. Miles de personas fueron reubicadas a partir de 1969 en los Núcleos Habitacionales Transitorios. Sin embargo, su carácter transitorio no habría de ser tal: el traslado hacia complejos habitacionales nunca ocurrió, y estos Núcleos devinieron en formas precarias de hábitat permanente, mientras la población en las villas de la ciudad de Buenos Aires seguía creciendo.

La política del Plan de Erradicación de Villas de Emergencia osciló entre la promoción social, el asistencialismo y la utilización de métodos compulsivos y violentos, dando lugar a las primeras prácticas expulsivas sistemáticas hacia los sectores populares. Los procedimientos utilizados se basaron en el control de las familias que habitaban estos barrios y en la requisa de sus viviendas, reeditando las medidas higiénicas hacia los pobres y sus formas de residencia en períodos anteriores. Se proponía la construcción de grandes conjuntos urbanos con el objeto de moralizar las pautas de vida de los villeros, y que ello posibilitara modificaciones en la vida de los grupos beneficiarios con "poca adaptación a la vida urbana"23. De modo que esta época estuvo signada por ideas de progreso en que los sectores populares debían pasar por determinados

23 Clichevsky y Abba, 1980, p. 41. estadios evolutivos hasta alcanzar una forma de vida "civilizada".

El autoritarismo constituyó, así, la norma en los procedimientos de la política urbana durante la dictadura del general Onganía.

Tras siete años de gobierno militar, bajo el último gobierno de Juan Domingo Perón (1973-1976) las reivindicaciones villeras pudieron hacerse escuchar. Las organizaciones proponían la suspensión de los desalojos; la radicación y mejoras en los barrios existentes ${ }^{24}$; así como un acercamiento entre organizaciones villeras, sindicales (como la Confederación General del Trabajo de los Argentinos - central obrera opuesta a pactar con la dictadura de Onganía- y movimientos como los Sacerdotes para el Tercer Mundo con los cuadros técnicos de la Comisión Municipal de la Vivienda, de orientación predominantemente peronista.

Luego de ese breve período peronista, la violencia en las políticas destinadas al hábitat de los sectores populares recobró su virulencia a partir de la instalación de la dictadura militar más larga que conociera la historia argentina. En efecto, el nuevo período correspondiente a la última dictadura militar (1976-1983) fue paradigmático en cuanto al carácter acelerado, compulsivo y violento de las

24 Un ejemplo de esta experiencia fue la implementación del "Plan Piloto Villa 7" (Barrio Mataderos) que ante la fuerte participación de la población villera se propuso la radicación de este barrio. 
erradicaciones de viviendas populares. En gran medida, estas respondieron a intereses sobre un espacio urbano crecientemente valorizado, y a una política estatal que consideraba las villas y asentamientos como sitios insalubres, o espacios generadores de situaciones moralmente anómalas ${ }^{25}$.

La violenta erradicación de las villas durante este período formó parte de una política más amplia del gobierno militar (autodenominado "Proceso de Organización Nacional"), tendiente a la "elitización" de la Ciudad de Buenos Aires ${ }^{26}$. Este proceso consistió en recuperar la Capital para los sectores dominantes: la elite tradicional. Así, las características de la trama urbana en las villas -irregularidad constructiva, falta de servicios e infraestructura, hacinamiento-fueron consideradas incompatibles con el ideal de vida urbana: aquellos focos de contaminación e infección debían ser, pues, extirpados.

Las políticas habitacionales y urbanas implementadas durante este gobierno de facto no hicieron sino

25 Hermitte y Boivin, 1985; Blaustein, 2001.

26 Oszlak, 1991; Clichevsky, 2003. agravar la exclusión y segregación de los sectores populares que habitaban en la Ciudad de Buenos Aires. En efecto, aun cuando las políticas de erradicación incluyeran la promoción oficial de viviendas, estas se desplegaron en áreas periféricas para aprovechar los costos relativos menores del suelo urbano ${ }^{27}$. Frente a leyes más duras -que respondían a la lógica del mercado y a la implementación de grandes proyectos urbanos- la población que se alojaba en conventillos, hoteles e inquilinatos sufrió serios riesgos de desalojo. Si bien no hubo una política planificada de desalojo de estos habitantes - como en el caso de las erradicaciones de las villas implementadas por el municipio- se crearon serias restricciones en el acceso a la vivienda urbana para buena parte de la población de bajos ingresos económicos. La aplicación de normas, como la modificación del Código de Planeamiento Urbano ${ }^{28}$; la Ley de Alquileres ${ }^{29}$ del año 1977; la ley de ordenamiento territorial ${ }^{30}$ y el programa de construcción de autopistas -que favoreció la apropiación de

27 Caravaca Barroso y Villalón, 1992-1993.

28 La modificación del Código de Planeamiento Urbano exacerbó la estratificación social de la ciudad, restringiéndose las opciones de los sectores populares, al elevarse los precios de las viviendas y orientarse la construcción a los sectores de altos ingresos.

29 La ley de alquileres perjudicó a los sectores populares en los inquilinatos de la ciudad. Cerca de medio millón de inquilinos perdía la protección del Estado, debiendo apelar a soluciones más precarias que empeoraron sus condiciones habitacionales. Ver: Oszlak, 1991.

30 Esta ley prohibió nuevos loteos destinados a la población de bajos ingresos. 
renta en los terrenos céntricos- aumentó ostensiblemente las desigualdades y jerarquías en la urbe metropolitana.

El plan de erradicación de villas, en particular, trasladó compulsivamente a esta población hacia el conurbano bonaerense y, en menor medida, hacia el interior del país. Estos programas de erradicación masiva desatendieron la situación de vivienda de los damnificados tras su expulsión de la ciudad: una vez confinados a los límites externos de la ciudad "blanca y ordenada", los villeros sabrían donde asentarse; o, en su defecto, no era incumbencia de la autoridad de vivienda proveer una solución alternativa.

En contraste con los planes de erradicación aplicados por otros gobiernos, se impulsó la expulsión sin brindar alojamiento alternativo a la población afectada. Se concentraron en ese entonces todas las facultades en la Comisión Municipal de la Vivienda, la cual montó un operativo cuasi policial para desalojar compulsivamente a los moradores de las villas, derribando las casillas de los habitantes con topadoras. Estas últimas fueron el símbolo vivo que marcó la historia de estos barrios, inscrito en el cuerpo de las personas, convirtiéndose en un instrumento de amenaza por parte de la acción estatal. Las imágenes, recuerdos e historias contadas por quienes vivieron la topadora, se reactualizan ante nuevos rumores que aparecen a lo largo de la historia ante presuntos desalojos de los sectores populares.

Bajo la gestión del brigadier Osvaldo Cacciatore de la entonces Municipalidad de la Ciudad de Buenos Aires (1976-1982), la Comisión Municipal de la Vivienda actuó en tres etapas sucesivas. En primer lugar, la etapa de congelamiento impedía el crecimiento de los asentamientos y villas de emergencia en el ámbito de la ciudad capital. En segundo lugar, la etapa de desaliento persuadía a la población de abandonar los espacios que habían ocupado. Las medidas implementadas para efectivizar las expulsiones operaban -y operan aún hoy-a partir de actos intimidatorios: cortes de energía eléctrica, falta de recolección de residuos, rotura de caños, acumulación de escombros, retiro de paradas de colectivos y amenazas verbales. El desalojo indirecto ${ }^{31}$ involucrado en ese set de medidas amenazantes provocaba la creciente desafiliación de esos sectores, hasta alcanzar su corolario en la práctica de erradicación propiamente dicha.

La erradicación de villas y demás medidas de regulación del espacio urbano mencionadas -tales como la liberalización del mercado de alquileres y la reforma del código de edificación-dejaron como saldo la expulsión de un significativo número de habitantes de la ciudad. La Comisión Municipal de

31 Bartolomé, 1985. 
la Vivienda registraba para 1976 -primer año del gobierno dictatorial- 225 mil villeros ${ }^{32}$. En un año esta población se redujo a 146 mil; y para 1978, a 115 mil. Esta cifra se redujo a menos de la mitad para el año siguiente: 51.845 habitantes en 1979, para llegar en 1980 a tan solo 40.553 habitantes.

La lógica que subyacía al diseño y ejecución de esta política de erradicación fue la misma que una década antes había impulsado la construcción de los Núcleos Habitacionales Transitorios, y quedó cabalmente expresada por el entonces titular de la Comisión Municipal de la Vivienda, quien sostuvo que "vivir en Buenos Aires no es para cualquiera sino para el que lo merezca, para el que acepte las pautas de una vida comunitaria agradable y eficiente. Debemos tener una ciudad mejor para la mejor gente" 33 .

La intensificación de las erradicaciones hacia fines de la década de 1970 se relacionó con la inminencia del Mundial de Fútbol de 1978. Por este motivo, la gran limpieza se concentró en las villas de la zona norte, especialmente en las cercanías al estadio River Plate. La primera gran experiencia de erradicación con la dictadura se produjo entre fines de 1977 y comienzos de 1978 en la Villa del Bajo Belgrano, que ocupaba unas once manzanas próximas al gran estadio mundialista. A la Villa del Bajo Belgrano le siguió la de Colegiales, ubicada

32 Blaustein, 2001

33 Revista Competencia, 1980, citado en Oszlak, 1991, p. 78. sobre terrenos del Ferrocarril Mitre, ambas en la zona norte de la ciudad. Mientras tanto, comenzó la erradicación de la Villa 31 de Retiro, ubicada en el centro, la cual fue casi totalmente eliminada. Y, para 1979, comenzó la erradicación de la Villa del Bajo Flores (1-11-14), el asentamiento más grande de la ciudad ${ }^{34}$.

De este modo, las políticas urbanas implementadas durante el período dictatorial inauguraron un proceso de restructuración excluyente del espacio urbano que -tal como veremos en los apartados que siguen-hoy en día sigue condicionando las prácticas de acceso a la ciudad de los sectores populares.

No obstante las políticas de expulsión violenta de los sectores populares, muchos de sus vecinos se organizaron mediante la creación de cooperativas de vivienda con proyectos de autoconstrucción en la periferia, en algunos casos con apoyo de la iglesia para interceder ante el autoritarismo estatal. En este sentido, la población desplazada apeló a vínculos de reciprocidad y desplegó sus recursos sociales no sólo como mecanismo de supervivencia, sino también con fines de producción, lo que se tradujo en el trabajo de dichas cooperativas a lo largo de ese período.

Como respuesta al plan de erradicación de villas, las familias afectadas interpusieron recursos de

34 Blaustein, 2001. 
amparo para detener los desalojos. La problemática se viabilizó mediante la judicialización a través de declaratorias de no innovar, de manera de impedir la demolición de viviendas.

En este sentido, se sostiene que las políticas habitacionales implementadas durante la dictadura no lograron desterrar las cotidianas impugnaciones de los afectados al pretendido orden urbano excluyente $^{35}$. En los años que siguen, los reclamos de los villeros cobrarán cierta legitimidad ante el accionar estatal, y las ocupaciones de inmuebles abandonados y terrenos baldíos se constituirán en un nuevo tipo de respuesta masiva frente a la coyuntura de expulsión de sectores populares de la ciudad capital.

\section{Las políticas de omisión y tolerancia}

Hasta aquí nos hemos enfocado en caracterizar la lógica de los desalojos compulsivos, desplegada básicamente por parte de los regímenes dictatoriales en Argentina durante el último medio siglo.

A partir de la década del 70 comienza a vislumbrarse un nuevo paradigma a nivel regional en materia de políticas habitacionales hacia los asentamientos

35 Verón, 2003.

204 revista invi 31(88): 193-215, noviembre de 2016 urbanos informales. Los programas de radicación constituyeron un nuevo giro generalizado propugnado por organismos internacionales, tales como el Banco Mundial ${ }^{36}$. Paulatinamente, en los países de la región se procura lograr la inserción de sus habitantes en la ciudad, a través de iniciativas puntuales de urbanización de áreas informales con provisión de infraestructura y servicios básicos. En Argentina, no será hasta después del período dictatorial que vendrá un cambio de paradigma: la radicación e integración de la población villera, a partir de la década de 1980. El fracaso en el intento de erradicar supuso, entonces, la aparición de nuevos desafíos para la gestión urbana, ligados a la articulación entre las instituciones y los actores sociales villeros. Tras el fin de la dictadura, las políticas de erradicación, desalojos y relocalizaciones fueron cediendo lugar a tendencias de mayor tolerancia hacia las villas de emergencia, aunque no así respecto a los asentamientos, que son objeto de políticas de omisión o expulsión.

Con el retorno a la democracia en 1984 comenzó el "operativo retorno": las familias expulsadas durante la dictadura fueron volviendo a la ciudad. Tras la drástica reducción poblacional que sufrieron las villas porteñas durante la dictadura, la población en villas de emergencia creció un 400\% durante el período 1983-1991. Entre 1991 y 2001, se duplicó la cantidad de hogares registrados en villas: pasó

36 Valladares, 1981. 
de representar 12.150 hogares en 1991 a 28.125 en el censo $2001^{37}$.

El regreso a la ciudad de los sectores populares que habían sido expulsados estuvo facilitado por cierto ablandamiento de las políticas habitacionales. En efecto, bajo la presidencia de Raúl Alfonsín (1983-1989) se sostuvo y fortaleció el principio de radicar definitivamente las villas de emergencia de la ciudad, buscando garantizar la permanencia de la población en los terrenos ocupados ${ }^{38}$. Durante los primeros años del gobierno alfonsinista prevaleció un discurso que buscaba distanciarse de las políticas urbanas de la dictadura. Asimismo, se diseñaron una serie de políticas tendientes a reconocer la producción del hábitat preexistente, que tendría una línea de continuidad durante la década siguiente. Algunas de estas políticas fueron el Programa de Radicación y Solución Integral de Villas y NHT; el Decreto 1001 de 1990 de transferencia de tierras e inmuebles; la Ordenanza 44.873 -que incorporó a las villas como distritos de zonificación en el Código de Planeamiento Urbano-; el reconocimiento del principio de radicar las villas en la sanción de la Constitución de la Ciudad de Buenos Aires, en 1995, junto al reconocimiento del derecho a una vivienda digna y a un hábitat adecuado; la Ley 148/98 que estableció

37 Censos de Población y Vivienda, 1991 y 2001.

38 Martínez, 2003. la prioridad de la problemática habitacional en las villas; el Programa de Radicación, Integración y Transformación de Villas y NHT de 2001, donde se siguió ratificando la legalidad y legitimidad de los reclamos históricos de hábitat digno, entre otras iniciativas ${ }^{39}$.

Las medidas enumeradas -que forman parte de lo que denominamos politicas de tolerancia- pueden ser consideradas como portadoras de un principio democratizador de las relaciones sociales y del planeamiento urbano, ya que reconocieron las demandas y reivindicaciones de los movimientos villeros, por tantos años aplazadas. Sin embargo, estas se conjugaron con su contraparte, las politicas de omisión, a través de las cuales los sectores populares quedaron, en la práctica, relegados de transformaciones significativas, dados los alcances muy exiguos de las políticas de radicación. En efecto, más allá de los postulados formales, pocas transformaciones efectivas ocurrieron.

Las políticas de radicación estuvieron asociadas a dos objetivos ${ }^{40}$ : consolidar la urbanización del hábitat, regulando el proceso de urbanización; y asegurar la regularización del dominio, garantizando el acceso a la propiedad de la tierra. Así, las intervenciones realizadas en este período partían

39 Para una explicación más detallada sobre las políticas de radicación durante la década 1980-1990, véase Martínez, 2003 y Vitale, 2009.

40 Clichevsky, 1997. 
del supuesto de que la integración física traería la integración social. La pavimentación y apertura de calles fueron entonces la modalidad privilegiada -si bien limitada- de incorporar las villas al "resto de la ciudad". La regulación de la tenencia de tierra, en cambio, fue más conflictiva, como quedó en evidencia tras el fracaso del intento de traspasar la propiedad de los terrenos de la Villa 31 de Retiro a sus ocupantes, por tratarse de tierras de alta valoración económica, o -tal como sucedió en otros casos- por tratarse de terrenos privados con propietarios renuentes a efectivizar el traspaso. Así, la debilidad de las políticas de radicación de villas lo fue tanto en términos presupuestarios como en la falta de disponibilidad de tierras para reconocer la legitimidad del reclamo de los villeros de permanecer en las zonas ocupadas. La transferencia del dominio de las tierras y la regulación del proceso de urbanización en las villas de la ciudad se vieron, en fin, severamente limitadas ${ }^{41}$.

Por otra parte, las restricciones de las políticas de radicación pueden comprenderse en el marco de los cambios profundos que produjo la neoliberalización en las políticas habitacionales, durante los años '90, que implicaron "un deslizamiento de la condición de vivienda como política social a su

41 Además, la dificultad de recuperar las viviendas precarias y garantizar una regularización dominial se vio profundizada por el crecimiento de la población de las villas, añadiendo una mayor complejidad a su ya compleja implementación. transformación en mercancía"42. El reconocimiento legal del derecho a la vivienda que tuvo lugar en esta década supuso, como contracara, el desmantelamiento de los mecanismos que podrían haberlo hecho efectivo ${ }^{43}$.

Las políticas de omisión también se hicieron manifiestas en la incapacidad estatal de resolver la problemática habitacional. Si bien se incorporó a las organizaciones villeras al proceso de toma de decisiones -otorgando cierta legitimidad a sus reclamos históricos- durante la década del 90 se siguieron llevando a cabo prácticas intimidatorias y desalojos. Estas políticas expulsivas ya no estuvieron enfocadas primordialmente en las poblaciones de villas sino en asentamientos informales no reconocidos por el poder local y en ocupaciones de inmuebles en áreas céntricas o controvertidas de la ciudad, tal como veremos en el próximo apartado.

El saldo de estas dos décadas de erráticas políticas habitacionales se expresó en un aumento significativo del déficit habitacional y la emergencia de nuevas formas precarias del habitar, que son percibidas además como atrevidas o directamente inadmisibles para ciertos sectores de las clases medias.

42 Cravino, 2000, p. 25-26.

43 Vitale, 2009. 


\section{La iluminación funcional y el desalojo ejemplar de las casas tomadas}

Como señalamos sucintamente en la introducción, la toma de baldíos e inmuebles en la ciudad de Buenos Aires alude a individuos o familias de sectores populares que "rompen candado" y organizan su vida cotidiana en viviendas públicas o privadas abandonadas; piezas de inquilinatos que devienen "intrusadas" por el cese de pago; depósitos o fábricas cerradas u otros lugares ociosos de la ciudad, sin mediar vínculo legal con sus propietarios. Su origen se vinculó, en primera instancia, a manifestaciones espontáneas y en pequeña escala, protagonizadas por inquilinos desalojados de inquilinatos y hoteles, sumado a la existencia de un parque físico desocupado de alrededor del 15\% del total. En este sentido, apareció con "voz propia" en los medios periodísticos hacia finales de 1982 y comienzos de 1983, incluyendo su correlato: los desalojos, señalándose algunos casos identificables como una orden franciscana en el barrio de San Telmo, viviendas en Palermo y una vivienda ocupada en la calle Mario Bravo de este mismo barrio ${ }^{44}$.

44 Cuenya 1988.
Paralelamente, las políticas de viviendas sociales implementadas por diferentes organismos del Estado fueron reconfiguradas como políticas urbanas vinculadas a la acción del mercado y a la actuación de diferentes grupos sociales implicados en los procesos de renovación urbana. Respecto a esto último, se fueron tomando medidas que impactaron negativamente sobre los sectores populares en la ciudad. Por ejemplo, en la zona sur-de mayor concentración de estos sectores- se modificó la normativa del área histórica de la ciudad, con un criterio de flexibilización de inversiones, en la recuperación de Puerto Madero y Retiro, y en la concreción de obras viales (autopistas). La recuperación de estas zonas ${ }^{45}$ llevó a la profundización de efectos expulsivos hacia sectores de bajos recursos económicos ${ }^{46}$.

Algunos autores señalan que el fenómeno de las ocupaciones dejó de ser invisible a partir de la tendencia a la expulsión, por parte del Estado, de los sectores populares del espacio urbano, en respuesta a la demanda de los sectores concentradores de poder económico que requerían espacios de localización central y fácil acceso ${ }^{47}$. Si bien este proceso efectivamente ocurre desde la década del noventa, dicha expulsión no trajo aparejada más que una visibilización temporaria, justificada por

\footnotetext{
45 Mignaqui, 1995; Coraggio, 1997; Ciccolella, 1999; Cuenya, 2000; Prevot Schapira, 2000.

46 Herzer, 2008; Mutuberria Lazarini y Rodríguez, 2005.

47 Jeifetz et al., 1994 citado en Procupez, 1995
} 
la expulsión misma, que denominamos iluminación funcional. El "desborde" de las casas tomadas se visibilizaba para la condena social y como preludio de un desalojo pedagógico. Una vez que se lograba el objetivo de la expulsión, luego de algún momento de auge de la problemática, esta volvía a sumirse en la más profunda oscuridad de la trama urbana.

Tal fue el caso, por ejemplo, de los desalojos ze produjo otro momento de iluminación funcional de las casas tomadas por parte del Estado y los medios de comunicación, que luego hubo de derivar-como ya había sucedido cinco años atrás- en un recrudecimiento de la política oficial hacia aquel grupo de los sectores populares. Los medios de comunicación dedicaron una enorme cobertura a tratar otra vez, en forma conjunta, algunas usurpaciones resonantes de la ciudad de Buenos Aires y la problemática de inmigrantes de países vecinos como Bolivia y Perú; casi como si se estuviera aludiendo a la causa y efecto de un mismo fenómeno.

Igual que en la época de las bodegas Giol o el solar histórico de Flores, aquí las ocupaciones cobraron una máxima visibilidad en un mínimo de tiempo: todos los casos comentados fueron tratados por los medios de comunicación, prácticamente, en el transcurso de la misma semana. El Gobierno también iluminó funcionalmente la problemática tomando cartas en el asunto: por un lado, dispuso endurecer las leyes migratorias y por otro, se sucedieron una serie de allanamientos y operativos policiales que tuvieron como blanco a inmigrantes bolivianos y peruanos. El proyecto de ley disponía mayores facilidades en la expulsión de los migrantes en relación a delitos leves -como podría ser la usurpación- y multas a quienes les dieran alojamiento ${ }^{48}$.

Como señala Grassi, "si [en el Estado Neoliberal] la vivienda, la educación, el trabajo, el salario, etc., pierden su condición de derechos (constitutivos de sujetos colectivos) para ser recursos cuyo acceso regula únicamente el mercado, el no acceso deja de constituir un problema del Estado, para devenir un problema de particulares"49. En efecto, diversos autores coinciden en señalar que la vivienda es crecientemente definida y aceptada como un bien privado que debe adquirirse en el mercado a partir de capacidades individuales ${ }^{50}$. Ejemplo de ello es cómo a partir de la década del '90, y en el marco de una profunda reestructuración del Estado como producto de los imperativos del sistema financiero global, se agravó el proceso de deconstrucción de la vivienda social. En el ámbito específico de la ciudad de Buenos Aires, no resulta excesivo afirmar que las políticas habitacionales oscilan entre

48 Diario Clarín, 1 febrero 1999.

49 Grassi, Hintze y Neufeld, 1994, p. 22.

50 Cfr. Puertas, 1999. 
el exceso de restricciones, el clientelismo político, la escasez y el absurdo que, a diferencia del modus operandi que primó durante la dictadura, en la década de los '90 es expulsado de ella en forma sutil y casi inadvertida. Sin embargo, la expulsión configura solo una de las facetas de este Estado que se presenta como un Estado "bifronte, como un Jano que castiga y a la vez trata de reparar en parte sus excesos" $"$.

Como lo demostraron una serie de episodios emblemáticos de los años 90 y comienzos del 2000 a escala nacional (el estado de sitio o la represión a propósito de cacerolazos, piquetes urbanos y cortes de ruta), la violencia estatal se mantuvo "a la orden del día". Si la política de legitimación del Estado Neoliberal oscila "entre el asistencialismo y la represión"52, tal contrapunto se expresa, en las políticas habitacionales, en la simultánea existencia de subsidios habitacionales que no solucionan el problema de la vivienda (el asistencialismo) y los desalojos ejemplares (la represión).

En rigor, dichos subsidios conforman un encubrimiento de la violencia de cualquier expulsión. La contracara de la violencia inadvertida -vale decir,

51 Oszlak, 1991, p. 31-32.

52 Ibídem, 1994, p. 22. la violencia explícita- se corporiza en los casos en que se vuelve imprescindible -desde cierta lógica dominante- disciplinar el exceso de ocupaciones sobre la ciudad, ya sea por su presencia en barrios demasiado prestigiosos (como las bodegas Giol en Palermo), o por invadir parte del patrimonio público, como el caso del solar histórico del barrio de Flores (1993) o el edificio del ex Patronato de la Infancia en San Telmo (2003). El violento desalojo de los ocupantes del ex PADELAI en febrero de 2003 reedita lo que denominamos la iluminación funcional en servicio de un desalojo ejemplar. En este caso, la medida aleccionadora iba dirigida hacia los espacios "recuperados" por asambleístas a lo largo de 2002, que fueron progresivamente "desmantelados", en su vasta mayoría, en $2003^{53}$.

Lo interesante de los casos reseñados es que la violencia se ejercita, no azarosamente, contra un grupo preciso de habitantes precarios de la ciudad: los ocupantes de inmuebles.

53 El 20 de diciembre de 2001, miles de personas salieron a la calle en repudio a las medidas políticas y económicas que llevaron al estado de crisis, y aglutinaron diversos sectores que comenzaban a ocupar las calles. Aquí nacen las asambleas barriales, las cuales recuperaron espacios públicos o privados abandonados -reemplazando el concepto de "ocupación" por el de "recuperación". 


\section{Conclusiones}

A lo largo de este trabajo hemos analizado el carácter pendular de las políticas habitacionales, en cuanto a las tendencias para con los habitantes de villas, asentamientos y casas tomadas en la Ciudad de Buenos Aires. A las políticas de erradicación basadas en la violencia explícita durante los períodos dictatoriales le sucedieron abordajes tendientes a la tolerancia con la radicación de la población villera, fundamentalmente a partir del retorno a la institucionalidad democrática en Argentina.

Asimismo, los desalojos compulsivos y posteriores traslados a Núcleos Habitacionales Transitorios durante la década del 70 también dan cuenta, en forma emblemática, del carácter fallido de las políticas habitacionales de la ciudad de Buenos Aires. Las prácticas consuetudinarias de erradicación constituyen así a la transitoriedad como un mecanismo político de solución habitacional "definitiva” posible. La contradicción respecto a la naturaleza transitoria en su concepción y el carácter permanente en el desarrollo histórico de este tipo de solución habitacional habla por sí misma. En este temprano paradigma de la erradicación -que no hará sino reforzarse en etapas posteriores- ya comparece una preocupación oficial por la readaptación moral o conductual de la población villera, que encontró fundamento en la Teoría de la Marginalidad, según la cual existían en las ciudades de América Latina barreras culturales concentradas en las poblaciones marginales, que impedían el progreso de sus habitantes de lo tradicional a lo moderno ${ }^{54}$.

A nivel local, el paradigma de la erradicación encuentra su máxima expresión durante la última dictadura, que plantea la incompatibilidad entre las formas de vida en villas y asentamientos con el modo urbano propuesto de una ciudad solo para aquellos que la merecen. Vale decir, una convivencia contradictoria entre los lugares donde en apariencia se desarrollan la delincuencia, la marginalidad y el deterioro, y una ciudad donde reside la gente decente y donde se afirman los valores de orden, equidad, bienestar y pulcritud propios de la sociedad burguesa, poniendo de manifiesto una nueva concepción sobre la jerarquía del espacio urbano.

A partir del regreso de la democracia (1983) se produce una ruptura con las políticas erradicadoras y se procura integrar social y urbanísticamente a la población villera, aunque ya con una diferenciación espacial sobre los terrenos que pueden volver a ser habitados.

54 La solución política ante este problema era la eliminación física de estos espacios urbanos informales. 
En lo que concierne a los períodos caracterizados por políticas de radicación, se han mostrado ciertos rasgos de tolerancia que se manifiestan en el espíritu de las normativas sancionadas, si bien muchas de ellas han tenido una débil implementación. Pese a que este paradigma de la radicación ha implicado una mayor participación y respeto por las organizaciones villeras, no ha existido un correlato en la materialización de las propuestas. En efecto, los avances han sido poco significativos en cuanto a regularización dominial y articulación territorial.

Ahora bien, ¿por qué las políticas de radicación no significaron el fin de los desalojos, o siquiera un avance concreto hacia la solución del problema habitacional? ¿Acaso hay una aceptación más o menos tácita de que los pobres deben ser desplazados de la ciudad?

Si bien hemos consignado políticas de radicación e integración de villas, lo cierto es que el hábitat de los sectores populares no ha sido por lo general legitimado como un problema social relevante a ser incluido en la agenda pública. Las políticas estatales adoptaron mecanismos que tendieron a desplazar a los sectores populares ubicados en zonas controvertidas de la ciudad, naturalizando que los pobres urbanos no pueden habitar en ellas. En efecto, una política de deconstrucción de la vivienda social opera a partir de una violencia eufemizada que elude los mecanismos explícitos de violencia desarrollados en períodos anteriores.

Como hemos visto, las políticas de vivienda popular no hicieron sino reproducir el problema habitacional; la compleja trama de desalojos y soluciones inadecuadas agrava una y otra vez el déficit habitacional que se dice combatir. La violencia del aparato estatal que produce expulsión y desplazamiento se traslada a nuevos actores ahora estigmatizados, sin dejar de existir en ninguno de los períodos que hemos analizado.

La caracterización histórica de los desalojos de sectores populares nos permitió, además, reconstruir las lógicas políticas que les confirieron sentido, comparando continuidades y rupturas de los procedimientos institucionales en diferentes contextos políticos. Asimismo, se indagó sobre la contradicción entre los procesos de inclusión de las políticas de radicación, y los simultáneos procesos de segregación y exclusión de los sectores populares que habitan en distintas zonas de la ciudad.

Hemos analizado hasta aquí las contradicciones entre la integración y la exclusión en las políticas habitacionales de la Ciudad de Buenos Aires entre 1950 y 2002. Un objeto de análisis pendiente es profundizar la comprensión de las modalidades de intervención predominantes en materia de hábitat popular en la actualidad. ¿Qué continuidades y 
rupturas encontramos con respecto a etapas precedentes? ¿Cuáles son los condicionantes del agravamiento sistemático del déficit habitacional durante la última década, coincidente con el período de mayor crecimiento económico de la historia argentina? ¿Cómo se aborda la emergencia habitacional? ¿Qué forma adquiere la tensión constante, identificada en este trabajo, entre la inclusión y la imposición de un orden que justifica desalojos y expulsiones? Estas son algunas de las interrogantes que nos proponemos abordar en un trabajo futuro, a fin de delinear la trayectoria de casi un siglo de políticas habitacionales hacia los sectores populares porteños, cuyos signos prevalecientes son la errancia, la parcialidad y la violencia.

\section{Bibliografía}

BARTOLOMÉ, Leopoldo José y RIBEIRO, Gustavo Lins. Relocalizados: antropología social de las poblaciones desplazadas. Buenos Aires, Instituto de Desarrollo Económico y Social. 1985.

BLAUSTEIN, Eduardo. Prohibido vivir aquí. Una historia de los planes de erradicación de villas de la última dictadura, Buenos Aires, Comisión Municipal de la Vivienda, Gobierno de la Ciudad Autónoma de Buenos Aires. 2001.

CARAVACA BARROSO, Inmaculada y VILLALÓN, Josefina Cruz. Crecimiento urbano y marginación social en Latinoamérica: actuaciones espontáneas y políticas de intervención. Boletín de la Asociación de Geógrafos Españoles. (15-16): 133-157, $1992-$ 1993. ISSN 0212-9426.

CARMAN, María. El principio de "máxima intrusión socialmente aceptable", o los diversos grados de legitimidad de las ocupaciones urbanas. Boletín de Antropología Universidad de Antioquia. 21(38): 130146, 2007. ISSN 2390-027X.

CICOLELLA, Pablo. Globalización y dualización en la Región Metropolitana de Buenos Aires. Grandes inversiones y reestructuración territorial en los años 90. EURE. 25(76): 5-27, 1999. DOI 10.4067/ S0250-71611999007600001.

CLICHEVSKY, Nora. Territorios en pugna: las villas de Buenos Aires. Ciudad y territorio. Estudios territoriales. (136-137): 347-374, 2003. ISSN 1133-4762.

--- Informalidad y segregación urbana en América Latina. Una aproximación. Santiago de Chile, CEPAL. 2000 .

--- Regularización dominial: ¿solución para el hábitat popular en un contexto de desarrollo sustentable? En: CUENYA, Beatriz; FALU, Ana. Reestructuración del Estado y política de vivienda en Argentina. Buenos Aires, Centro de Estudios Avanzados, Oficina de Publicationes del CBC, Universidad de Buenos Aires. 1997.

CLICHEVSKY, Nora y ABBA, Artemio. Diseño y modo de uso de los conjuntos habitacionales. Revista Ambiente. (22):35-51, 1980.

CORAGGIO, José Luis. Descentralización el día después... Buenos Aires, Universidad de Buenos 
Aires. 1997. Cuadernos de Postgrado, Serie Cursos y Conferencias.

CRAVINO, Cristina. La política de radicación de villas. El caso de la Ciudad de Buenos Aires, Buenos Aires, Mimeo. 2000.

CUENYA, Beatriz. Cambios, logros y conflictos en la política de vivienda en Argentina hacia fines de siglo. Seminario Internacional Gestión Local y Políticas Habitacionales. Universidad Nacional de Rosario, Mimeo, 2000.

--- Descentralización y política de vivienda en Argentina. Argentina, Centro de Estudios Avanzados. Oficina de Publicaciones del CBC. Universidad de Buenos Aires. 1997.

--- Inquilinatos en la ciudad de Buenos Aires. Referentes teóricos e históricos y un estudio de caso en el barrio de Almagro. Buenos Aires, CEUR. 1988. Cuadernos del CEUR 24.

DUCCI, María Elena. El lado oscuro de una política de vivienda exitosa. EURE. 23(69): 99-115, 1997. ISSN 0250-7161.

FIGUEROA SALAS, Jonás. El territorio baldío. Aproximación teórica a las políticas territoriales iberoamericanas. Ciudad y territorio: Revista de ciencia urbana. (79): 51-60, 1989. ISSN 0210-0487.

GEISSE, Guillermo. El acceso de los pobres a la tierra urbana: tres problemas críticos de políticas. EURE. 9(25): 73-82, 1982. ISSN 0250-7161.

GRASSI, Estela; HINTZE, Susana y NEUFELD, María Rosa. Políticas sociales. Crisis y ajuste estructural: un análisis del sistema educativo, de obras sociales y de las políticas alimentarias. Buenos Aires, Espacio Editorial. 1994.

HARDOY, Jorge y SATTERHWAITE, David. La ciudad legal y la ciudad ilegal. Ciudad y territorio: Revista de ciencia urbana. (71): 3-22, 1987. ISSN 0210-0487.

HAJEK, Ernst. Pobreza y medio ambiente en América Latina. Buenos Aires, CIEDLA/Conrad Adenauer. 1995

HERMITTE, Estela y BOIVIN, Mauricio. Erradicación de villas miseria y respuestas organizativas de sus pobladores. En: BARTOLOMÉ, Leopoldo y LINS RIBEIRO, Gustavo. Relocalizados: antropología social de las poblaciones desplazadas. Buenos Aires, Instituto de Desarrollo Económico y Social. 1985.

HERZER, Hilda. Con el corazón mirando al Sur: transformaciones en el sur de la ciudad de Buenos Aires. Buenos Aires, Editorial Espacio. 2008. Colección Desarrollo social y sociedad.

HIDALGO, Rodrigo. Cien años de política de vivienda social, cien años de expulsión de los pobres a la periferia de Santiago. En: CASTILLO, María José, ed. e HIDALGO, Rodrigo, ed. Cien años de política de vivienda en Chile. Santiago de Chile, Ediciones UNAB, 2007.

JARAMILLO, Samuel. El desenvolvimiento de la discusión sobre la urbanización latinoamericana: Hacia un nuevo paradigma de interpretación. En: JARAMILLO, Samuel y CUERVO, Luis Mauricio. 
Urbanización latinoamericana: nuevas perspectivas. Bogotá, Escala. 1993.

LEKERMAN, Vanina. Prácticas y costumbres de los grupos de poder encargados de implementar políticas habitacionales en la ciudad de Buenos Aires. Buenos Aires, Universidad de Buenos Aires, 2014. Tesis de doctorado.

MAC DONALD, Joan. ¿Cuántas casas faltan? El déficit a nivel nacional y regional. Santiago de Chile, Corporación de Promoción Universitaria. 1994. Documento de Trabajo 16.

MARTíNEZ, Clarisa. Juegos de reconocimiento del derecho al espacio urbano en la ciudad de Buenos Aires. El caso de la política de radicación de villas. Revista Lavboratorio. 6(16), 2003.

MIGNAQUI, lliana. Reestructuración global y reterritorialización de la región metropolitana de Buenos Aires. Reforma del Estado, políticas públicas divergentes y diferenciación socio-territorial. Santiago de Chile, Seminario Internacional sobre Impactos Territoriales de los Procesos de Reestructuración. 1995.

MUTUBERRIA LAZARINI, Valeria y RODRÍGUEZ, María Florencia. Análisis de los desalojos en la ciudad de Buenos Aires. Resistencias y reivindicaciones. Buenos Aires, Instituto de Investigaciones Gino Germani. 2005.

OSZLAK, Oscar. Merecer la ciudad. Los pobres y el derecho al espacio urbano. Buenos Aires, CEDES, Humanitas.1991.
PREVOT SCHAPIRA, Marie France. Segregación, fragmentación, secesión. Hacia una nueva geografía social en la aglomeración de Buenos Aires. Economía, sociedad y territorio. 2(7): 405-431, 2000. ISSN 1405-8421.

PROCUPEZ, Valeria. Ladrillo por ladrillo: construcción de identidad social en el marco de una cooperativa de vivienda. Buenos Aires Universidad de Buenos Aires, Facultad de Filosofía y Letras. 1995. Tesis de licenciatura.

PUERTAS, Andrés. Prácticas organizativas y percepciones de familias ocupantes sobre su situación habitacional. Una reconstrucción de la historia y los emprendimientos organizativos. El caso de la fábrica tomada "Súchar". 1999. Inédito.

RODRIGUEZ, Mara Carla. Vinculación entre organizaciones de sectores populares y el gobierno municipal. El caso de la Ex-AU3. Segundo Informe de Avance. Beca de iniciación UBACyT. 1994. Inédito.

VALLADARES, Licia do Prado. A Propósito da Urbanização de Favelas. Espaço y Debate. Revista de estudos regionais e urbanos. 1(2): 5-18, 1981.

VERON, Natalia. Desalojos en la ciudad de Buenos Aires: La producción de las categorías y los espacios de la asistencia habitacional. Quid 16: Revista del Área de Estudios Urbanos. (3): 181-205, 2003. ISSN 2250-4060.

VITALE, Pablo. La ley y la trama: villas y política pública en la ciudad. Apuntes sobre la trayectoria del Programa de Radicación, Integración y 
Transformación de Villas y Núcleos habitacionales Transitorios. En Jornadas de Jóvenes Investigadores, Área de Estudios Urbanos IIGG (5², 2009, Buenos Aires). Universidad de Buenos Aires.

YUJNOVSKY, Oscar. Claves políticas del problema habitacional argentino. Buenos Aires, Grupo Editor Latinoamericano. 1984. 
